\title{
Involvement of the CA3-CA1 Synapse in the Acquisition of Associative Learning in Behaving Mice
}

\author{
Agnès Gruart, ${ }^{1}$ María Dolores Muñoz, ${ }^{2}$ and José M. Delgado-García ${ }^{1}$ \\ ${ }^{1}$ División de Neurociencias, Universidad Pablo de Olavide, 41013 Sevilla, Spain, and ²Departamento de Investigación, Hospital Ramón y Cajal, 28034 \\ Madrid, Spain
}

\begin{abstract}
One of the brain sites more directly related with learning and memory processes is the hippocampus. We recorded, in conscious mice, the activity-dependent changes taking place at the hippocampal CA3-CA1 synapse during the acquisition, extinction, recall, and reconditioning of an associative task. Mice were classically conditioned to evoke eyelid responses using a trace [conditioned stimuli (CS), tone; unconditioned stimuli (US), shock] paradigm. A single electrical pulse presented to the Schaffer collateral-commissural pathway during the CS-US interval evoked a monosynaptic field EPSP (fEPSP) at ipsilateral CA1 pyramidal cells. The slope of evoked fEPSPs increased across conditioning sessions and decreased during extinction, being linearly related to learning evolution. In contrast, fEPSPs were not modified when evoked in control mice in the absence of a conditioning protocol. Long-term potentiation (LTP) evoked by high-frequency stimulation of Schaffer collaterals prevented acquisition, extinction, recall, or reconditioning, depending on the moment when it was triggered. Learning and memory impairments evoked by LTP induction resulted probably from the functional saturation of the CA3-CA1 synapse, although an additional disturbance of the subsequent information transfer toward postsynaptic circuits cannot be discarded. CGP 39551 [(E)-( \pm )-2-amino-4-methyl-5-phosphono-3-pentenoic acid ethyl ester] (an NMDA antagonist) prevented LTP induction in behaving mice, as well as the acquisition of an eyelid learned response, and the synaptic changes taking place at the CA3-CA1 synapse across conditioning. In conclusion, the responsivity of the CA3-CA1 synapse seems to be modulated during associative learning, and both processes are prevented by experimental LTP or NMDA-receptor inactivation. Our results provide evidence of a relationship between activity-dependent synaptic plasticity and associative learning in behaving mice.
\end{abstract}

Key words: hippocampus; mice; NMDA receptor; motor learning; eyeblink; LTP

\section{Introduction}

Acquired learning abilities are assumed to be stored in the form of functional and/or structural changes in synaptic efficiency (Hebb, 1949). Although there are many excellent studies in vitro of the electrophysiological processes and molecular events supporting activity-dependent synaptic changes (Bliss and Collingridge, 1993; Engert and Bonhoeffer, 1999; Malenka and Nicoll, 1999; Lynch, 2004), not much information is available on synaptic plasticity during actual learning in behaving animals. Functional changes evoked by learning should be susceptible to being detected at synapses relevant to the acquisition process. For example, it has been reported that inferior olive synaptic contacts on posterior interpositus neurons are potentiated during the acquisition of delay eyeblink conditioning (Gruart et al., 1997).

Another basic tenet is that long-term potentiation (LTP) is the mechanism underlying certain forms of learning (Bliss and Lømo, 1973; McNaughton et al., 1978). LTP is evoked by highfrequency stimulation (HFS) of selected afferent pathways result-

Received July 10, 2005; revised Dec. 3, 2005; accepted Dec. 5, 2005.

This work was supported by Spanish Ministerio de Ciencia y Tecnología Grant BFI2002-00936 and Junta de Andalucía Grant CVI-122. We thank María Sutil for her technical assistance and Roger Churchill for his editorial help.

Correspondence should be addressed to Dr. Agnès Gruart, División de Neurociencias, Universidad Pablo de Olavide, Ctra. de Utrera, Km. 1, 41013 Sevilla, Spain. E-mail: agrumas@upo.es.

DOI:10.1523/JNEUROSCI.2834-05.2006

Copyright $\odot 2006$ Society for Neuroscience $\quad$ 0270-6474/06/261077-11\$15.00/0 ing in a long-lasting enhancement of synaptic efficacy. The experimental induction of LTP will surely disturb the synaptic changes taking place during associative learning in selected neural sites. Indeed, it is known that LTP saturation of hippocampal circuits disrupts spatial learning (Barnes et al., 1994), and that place representation in hippocampal networks can be modified experimentally by LTP (Dragoi et al., 2003).

The hippocampus has been implicated in a variety of learning paradigms, including classical conditioning of eyelid responses (Berger et al., 1983; Sanchez-Andres and Alkon, 1991; McEchron and Disterhoft, 1997; Múnera et al., 2001). Bilateral hippocampal lesions impair the acquisition of trace eyeblink conditioning, whereas they do not alter delay conditioning (Thompson, 1988; Moyer et al., 1990). Apparently, whereas trace conditioning requires a conscious knowledge (Clark and Squire, 1998) and/or declarative or explicit memory (Eichenbaum, 1999) of relevant relationships between conditioned (CS) and unconditioned (US) stimuli, delay conditioning does not. Moreover, mice are capable of acquiring classically conditioned eyelid responses using trace paradigms (Takatsuki et al., 2003; Domínguez-del-Toro et al., 2004).

As already shown for dentate granule cells (Weisz et al., 1984), we studied here whether the acquisition of associative learning modifies the synaptic strength of the hippocampal CA3-CA1 synapse. We used classical conditioning of eyelid responses, with 
a trace paradigm, presenting a tone as CS and an electrical shock as US. We recorded, in vivo, the field EPSP (fEPSP) evoked at hippocampal CA1 pyramidal cells by the electrical stimulation of the Schaffer collateral-commissural pathway. The fEPSPs were evoked at CS-US intervals during habituation, acquisition, extinction, recall, and reconditioning of eyelid responses. LTP was experimentally evoked before selected conditioning sessions to determine its effects both on the acquisition of the associative learning and on the profile of evoked fEPSPs. Finally, $(E)-( \pm)-$ 2-amino-4-methyl-5-phosphono-3-pentenoic acid ethyl ester (CGP 39551) (an antagonist of the NMDA receptor) was administered in vivo to determine the involvement of this glutamate receptor on the three phenomena (i.e., LTP, synaptic enhancement, and associative learning) considered in this study (Bliss and Collingridge, 1993; Malenka and Nicoll, 1999). The present results provide substantial evidence of the intrinsic relationships between LTP, activity-dependent synaptic plasticity, and associative learning in mammals.

\section{Materials and Methods}

Subjects. Experiments were performed on 120 C57BL/6 male adult mice (3-5 months old; $28-35 \mathrm{~g}$ ) obtained from an official supplier (University of Granada Animal House, Granada, Spain). Before surgery, animals were housed in separate cages $(n=10$ per cage). The mice were kept on a $12 \mathrm{~h} \mathrm{light/dark} \mathrm{cycle} \mathrm{with} \mathrm{constant} \mathrm{ambient} \mathrm{temperature}\left(21 \pm 1^{\circ} \mathrm{C}\right)$ and humidity $(50 \pm 7 \%)$. Food and water were available ad libitum. Electrophysiological and behavioral studies were performed in accordance with the guidelines of the European Union Council (86/609/EU) and Spanish regulations (BOE 67/8509-12, 1988) for the use of laboratory animals in chronic experiments. Experiments were also approved by the Institution Committee for animal care and handling.

Surgery. Animals were anesthetized with $0.8-3 \%$ halothane (AstraZeneca, Madrid, Spain) delivered via a home-made mask. Halothane was administered from a calibrated Fluotec 5 (Fluotec-Ohmeda, Tewksbury, $\mathrm{MA}$ ) vaporizer at a flow rate of $1-4 \mathrm{~L} / \mathrm{min}$ oxygen. Once anesthetized, animals were implanted with bipolar stimulating electrodes on the left supraorbitary branch of the trigeminal nerve and with bipolar recording electrodes in the ipsilateral orbicularis oculi muscle (see Fig. $1 \mathrm{~A}$ ). Electrodes were made of $50 \mu \mathrm{m}$, Teflon-coated, annealed stainless steel wire (A-M Systems, Carlsborg, WA), and with their tips bared of the isolating cover for $\approx 0.5 \mathrm{~mm}$. The electrode tips were bent as a hook to facilitate a stable insertion in the upper eyelid. Stereotaxic coordinates (Paxinos and Franklin, 2001) were followed to implant animals with bipolar stimulating electrodes aimed at the right (contralateral) Schaffer collateral-commissural pathway of the dorsal hippocampus ( $2 \mathrm{~mm}$ lateral and $1.5 \mathrm{~mm}$ posterior to Bregma; depth from brain surface, $1.0-1.5 \mathrm{~mm}$ ) and with two recording electrodes aimed at the ipsilateral stratum radiatum underneath the CA1 area ( $1.2 \mathrm{~mm}$ lateral and $2.2 \mathrm{~mm}$ posterior to Bregma; depth from brain surface, $1.0-1.5 \mathrm{~mm}$ ). These electrodes were made of $50 \mu \mathrm{m}$, Teflon-coated tungsten wires (Advent Research Materials, Eynsham, England). The final position of hippocampal stimulating and recording electrodes was determined under recording procedures explained below. A $0.1 \mathrm{~mm}$ bare silver wire was affixed to the skull as a ground. The eight wires were connected to two four-pin sockets (RS Amidata, Madrid, Spain). The ground wire was also connected to the recording system with a single wire. Sockets were fixed to the skull with the help of two small screws and dental cement (Domínguez-del-Toro et al., 2004).

Classical conditioning procedures. For recordings, two animals at a time were placed in separate small $(5 \times 5 \times 10 \mathrm{~cm})$ plastic chambers located inside a Faraday box $(30 \times 30 \times 20 \mathrm{~cm})$. Classical conditioning was achieved using a trace paradigm (see Fig. $1 B$ ). For this, a tone $(20 \mathrm{~ms} ; 2.4$ $\mathrm{kHz} ; 85 \mathrm{~dB}$ ) was presented as a CS. The US consisted of a $500 \mu \mathrm{s}, 3 \times$ threshold, square, cathodal pulse. The US started $500 \mathrm{~ms}$ after the end of the CS. Unless otherwise indicated, a total of 4 habituation, 10 conditioning, and 5 extinction sessions were performed for each animal (see below). A conditioning session consisted of 60 CS-US presentations, and lasted $\approx 30 \mathrm{~min}$. In $10 \%$ of the cases, the CS was presented alone. CS-US presentations were separated at random by $30 \pm 5 \mathrm{~s}$. For habituation and extinction sessions, only the CS was presented, also for 60 times per session at intervals of $30 \pm 5$ s. For recall (i.e., retrieval), animals underwent two additional conditioning sessions $7 \mathrm{~d}$ after the 10th one. For pseudoconditioning, unpaired CS and US presentations were performed for 10 sessions (60 times/session). Pseudoconditioned animals also received four habituation and five extinction sessions, as indicated above (Domínguez-del-Toro et al., 2004).

Recording and stimulation procedures. Recordings were performed using Grass P511 differential amplifiers with a bandwidth of $0.1 \mathrm{~Hz}-10 \mathrm{kHz}$ (Grass-Telefactor, West Warwick, RI). Hippocampal recordings were performed with a high impedance probe $\left(2 \times 10^{12} \Omega ; 10 \mathrm{pF}\right)$. Reflex blinks were collected before conditioning sessions and evoked by single $50 \mu \mathrm{s}, 2 \times$ threshold, square, cathodal pulses presented at a rate of $1 / 30 \mathrm{~s}$ (see Fig. 1A). As criteria, we considered a "conditioned response" the presence, during the CS-US period, of electromyographic (EMG) activity lasting $>10 \mathrm{~ms}$ and initiated $>50 \mathrm{~ms}$ after CS onset. In addition, the integrated EMG activity recorded during the CS-US interval had to be at least 2.5 times greater than the averaged activity recorded immediately before CS presentation (Porras-García et al., 2005).

Electrodes were surgically implanted in the CA1 area using, as a guide, the field potential depth profile evoked by paired ( $20-50 \mathrm{~ms}$ of interval) pulses presented at the ipsilateral Schaffer collateral pathway. The recording electrode was fixed at the site where a reliable monosynaptic field EPSP was recorded (see Fig. $1 \mathrm{~A}$ ). Synaptic field potentials in the CA1 area were evoked during habituation, conditioning, and extinction sessions by a single $100 \mu \mathrm{s}$, square, biphasic (negative-positive) pulse applied to Schaffer collaterals $300 \mathrm{~ms}$ after CS presentation. Stimulus intensities ranged from 50 to $350 \mu \mathrm{A}$. For each animal, the stimulus intensity was set well below the threshold for evoking a population spike, usually $30-40 \%$ of the intensity necessary for evoking a maximum fEPSP response (Gureviciene et al., 2004). An additional criterion for selecting stimulus intensity was that a second stimulus, presented $20-50 \mathrm{~ms}$ after a conditioning pulse, evoked a larger $(>20 \%)$ synaptic field potential (Bliss and Gardner-Medwin, 1973). For evoking LTP, each animal was presented with five $200 \mathrm{~Hz}, 100 \mathrm{~ms}$ trains of pulses at a rate of 1 per second. This protocol was presented six times in total, at intervals of $1 \mathrm{~min}$. The 100 $\mu \mathrm{s}$, square, biphasic pulses used to evoke LTP were applied at the same intensity used for the single pulse presented after CS presentation. On occasions, some animals $(n=9)$ presented abnormal EEG responses after HFS; those animals were rejected from the study.

Drugs. The chemicals used were (E)-( \pm )-2-amino-4-methyl-5phosphono-3-pentenoic acid ethyl ester (CGP 39551) and 2,3-dioxo-6nitro-1,2,3,4-tetrahydrobenzo[f] quinoxaline-7-sulfonamide disodium salt (NBQX disodium salt) from Tocris Bioscience (Avonmouth, UK). The two drugs were dissolved in saline and administered intraperitoneally at doses of 6.5 and $15 \mathrm{mg} / \mathrm{kg}$, respectively. Control animals received the same volume of saline.

Experimental groups. As illustrated in Figure $1 B$, animals were divided into eight groups. Unless otherwise indicated, and for the sake of homogeneity, all experimental groups were composed of 10 successful animals. (1) Controls were habituated and conditioned as indicated. After conditioning, half of them were submitted to extinction sessions and reconditioned (Control-1), whereas the other half underwent two recall sessions. (2) The HFS-1 group received two HFS sessions 10 min before the beginning of the first two conditioning sessions. (3) The HFS-2 group received two HFS sessions $10 \mathrm{~min}$ before the fifth and sixth conditioning sessions. (4) The HFS-3 group received two HFS sessions 10 min before the ninth and 10th conditioning sessions. These animals had no extinction sessions, but (like the Control-2 group) underwent two recall sessions. (5) Animals of the HFS-4 group received habituation and conditioning, but not extinction, sessions. Seven days later, they received two HFS sessions 10 min before the two recall sessions. (6) The HFS-5 group received a training similar to that of the Control-1 group, but including two HFS sessions $10 \mathrm{~min}$ before the first two reconditioning sessions. (7) A group of animals was injected with CGP 39551 (6.5 mg/kg, i.p.) $30 \mathrm{~min}$ before each conditioning session. (8) The pseudoconditioned group received 4 habituation, 10 pseudoconditioning, and 5 extinction sessions. 
A
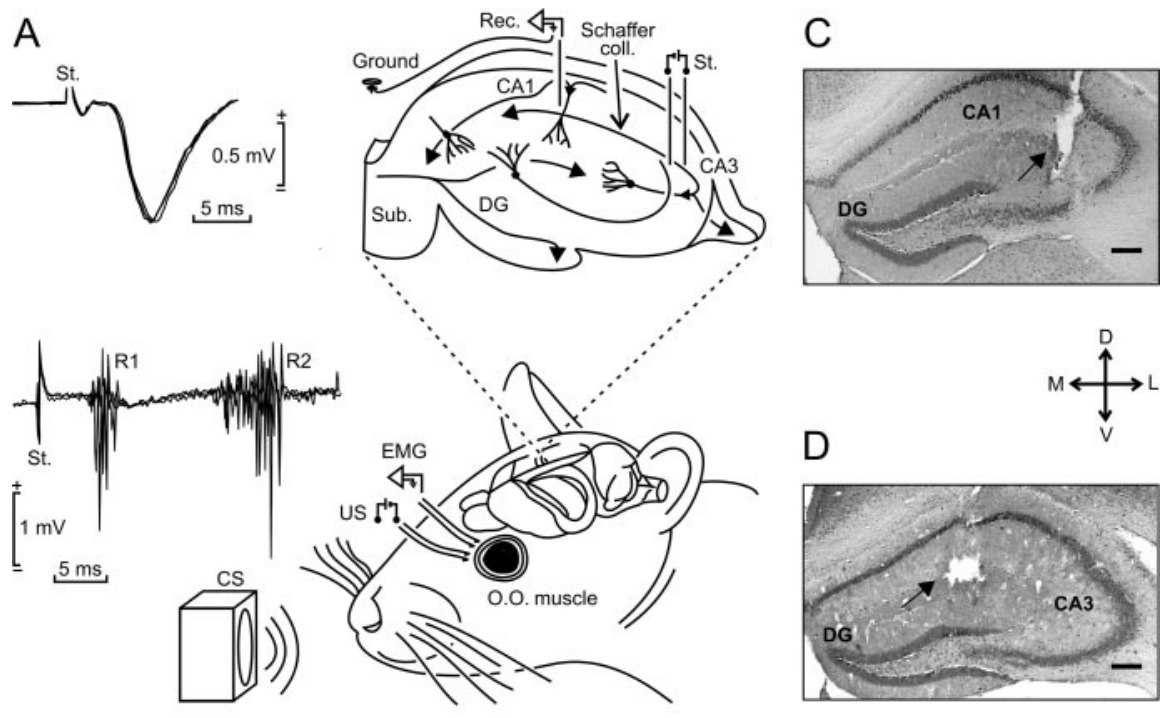

B
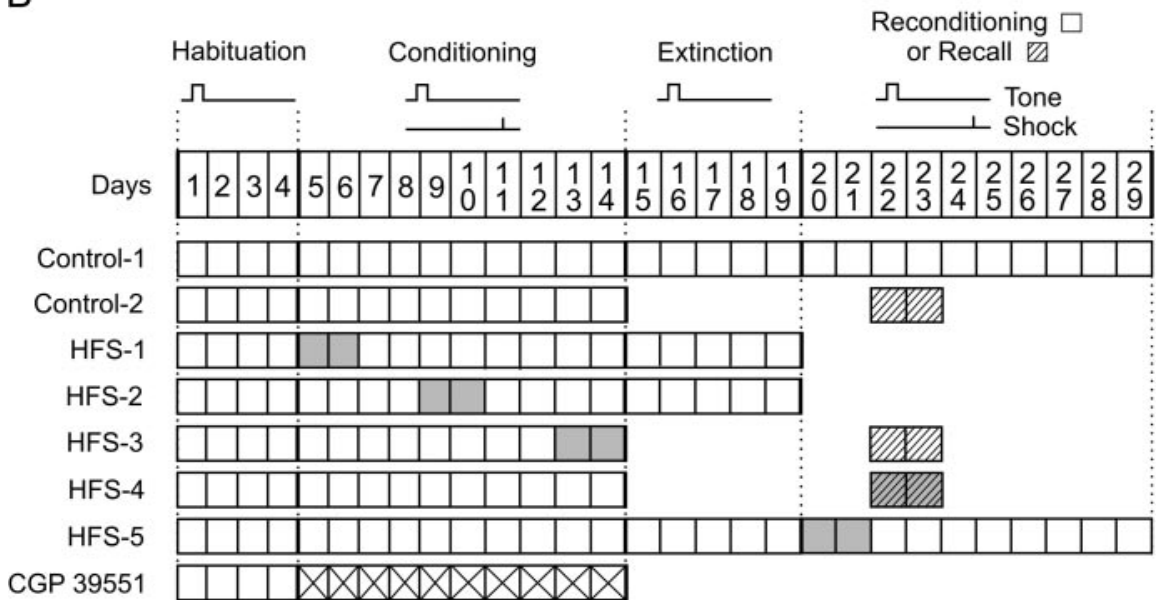

Figure 1. Experimental design. $\boldsymbol{A}$, EMG recording electrodes were implanted in the orbicularis oculi (0.0.) muscle of the upper left eyelid. Bipolar stimulating electrodes were implanted on the ipsilateral supraorbitary branch of the trigeminal nerve for presentation of US. For classical conditioning of eyelid responses, we used a tone $(20 \mathrm{~ms} ; 2.4 \mathrm{kHz} ; 85 \mathrm{~dB})$ as a CS. The loudspeaker was located $30 \mathrm{~cm}$ from the animal's head. As shown at the top right diagram, animals were also implanted with stimulating and recording electrodes aimed to activate CA3-CA1 synapses of the right (contralateral) hippocampus. The two superimposed recordings at the top left illustrate the extracellular synaptic field potential recorded (Rec.) at the stratum radiatum of the $\mathrm{CA} 1$ area after electrical stimulation (St.) of the Schaffer collaterals. Superimposed recordings at the bottom left correspond to the blink reflex evoked at the 0.0 . muscle by the electrical stimulation of the trigeminal nerve. Note the two short (R1) and long (R2) latency components characterizing the blink reflex in mammals. $\boldsymbol{B}$, Main experimental groups. All animals received four habituation and 10 conditioning sessions. In addition, some groups received five extinction or two recall (dashed boxes) sessions. Two groups (Control-1 and HFS-5) were reconditioned for $10 \mathrm{~d}$. The CGP 39551 group received this drug daily during the 10 conditioning sessions (crossed boxes). Gray boxes indicate when the HFS sessions were applied. $C, D$, Photomicrographs illustrating the location of stimulating ( $\boldsymbol{C}$ ) and recording (D) sites (arrows). Scale bars: $\boldsymbol{C}, \boldsymbol{D}, 200 \mu \mathrm{m}$. D, Dorsal; L, lateral; M, medial; $V$, ventral; DG, dentate gyrus; Sub, subiculum.

(9) A group of animals was presented with 60 stimuli/d at Schaffer collaterals, across $19 \mathrm{~d}$, but without CS or US stimuli. Stimuli were presented during $30 \mathrm{~min}$, at $30 \pm 5 \mathrm{~s}$ intervals. Finally, animals $(n=17)$ initially included in groups HFS- 1 to HFS- 5 that did not present a reliable potentiation ( $<20 \%$ increase in fEPSP slope, lasting $<30 \mathrm{~min}$ ) after the two HFS sessions were also conditioned. Data for this group are shown in Figure $7 C$ and $D$. Another 20 animals were used for preliminary trials, to calibrate the recording set-up, determine selected drug doses, and fix the recording procedures.

Histology. At the end of the experiments, mice were deeply reanesthetized (sodium pentobarbital; $50 \mathrm{mg} / \mathrm{kg}$ ) and perfused transcardially with saline and $4 \%$ phosphate-buffered paraformaldehyde. Selected sections

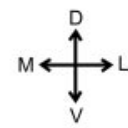

(50 $\mu \mathrm{m})$ including the dorsal hippocampus were mounted on gelatinized glass slides and stained using the Nissl technique with $0.1 \%$ toluidine blue to determine the location of stimulating and recording electrodes (see Fig. $1 C, D)$.

Data analysis. EMG and hippocampal activity, and one-volt rectangular pulses corresponding to CS and US presentations, were stored digitally on a computer through an analog/digital converter (CED 1401 Plus; Cambridge Electronic Design, Cambridge, UK), at a sampling frequency of $11-22 \mathrm{kHz}$ and an amplitude resolution of 12 bits. Commercial computer programs (Spike 2 and SIGAVG, from Cambridge Electronic Design) were modified to represent EMG and extracellular synaptic field potential recordings. Data were analyzed off-line for quantification of conditioned responses and the fEPSP slope with the help of homemade representation programs (Gruart et al., 1995, 2000; Domínguez-del-Toro et al. 2004; Porras-García et al., 2005). The slope of evoked fEPSPs was collected as the first derivative (i.e., volts per second) of fEPSP recordings (volts). For this, five successive evoked field synaptic potentials were averaged, and the mean value of the slope was determined for the rise time period (i.e., the period of the slope between the initial $10 \%$ and the final $10 \%$ of the evoked field potential). Computed results were processed for statistical analysis using the SPSS (Chicago, IL) for Windows package. Unless otherwise indicated, data are represented by the mean \pm SD. Collected data were analyzed using a two-way ANOVA test, with time or session as repeated measure, coupled with contrast analysis when appropriate. One-way ANOVA allowed checking the statistical differences between different groups. Regression analysis was used to study the relationship between the fEPSP slope and the percentage of conditioned responses.

\section{Results}

In vivo recordings of eyelid responses and of CA3-CA1 synaptic

\section{field potentials}

In a first series of experiments, we checked the functionality of the proposed experimental model. The electrical stimulation $(2 \times$ threshold) of the supraorbitary branch of the trigeminal nerve $(n=10$ animals) evoked an early EMG activation of the orbicularis oculi muscle at a latency of $5.3 \pm 1.2 \mathrm{~ms}$ (mean $\pm \mathrm{SD})$, followed by a second EMG activation with a latency from the stimulus of $18.6 \pm 3.2 \mathrm{~ms}$ (Fig. $1 \mathrm{~A}$, bottom recordings) These successive muscle activations correspond to the R1 and R2 components already described in humans (Kugelberg, 1952) and other species of mammals, including mice (Gruart et al., 1995, 2000; Domínguez-del-Toro et al., 2004). Electrode implantation did not seem to disturb the normal kinematics of spontaneous and reflexively evoked eyelid responses.

The electrical stimulation of Schaffer collaterals sometimes evoked an afferent volley into the CA1 area, usually appearing as a small triphasic (positive-negative-positive) potential, with a la- 
tency of $1.45 \pm 0.5 \mathrm{~ms}(n=15)$. The afferent volley was followed, 1.5-2 ms later, by a large negative wave when recorded at the stratum radiatum (i.e., on the apical dendrites of the CA1 pyramidal cells). The location of stimulating and recording electrodes in the hippocampus was checked at the end of the experiments and is illustrated in Figure $1 C$ and $D$. In approximately onefourth of cases, the wave recorded in the CA1 area presented a positive shape, corresponding to a more-dorsal location of the recording electrode (i.e., near the pyramidal cell layer) (Schwartzkroin, 1986).

In a preliminary study, we checked whether, in the absence of classical conditioning and/or HFS, the slope of fEPSPs evoked by the stimulation of Schaffer collaterals was stable across the maximum period of time used in this study (i.e., 29 d). For this, a group of animals $(n=10)$ was stimulated daily (60 single pulses for a 30 min period, with a time interval of $30 \pm 5 \mathrm{~s}$ ), during $29 \mathrm{~d}$. Quantitative analysis showed that the percentage of variation in fEPSP slopes across the last $25 \mathrm{~d}$, as compared with the mean value $(100 \%)$ computed from fEPSP slopes collected during the first four recording days, was $\leq 12.5 \%$, with no statistically significant tendency toward a decrease or increase $(p=0.71)$.

\section{Evolution of CA3-CA1 synaptic field potentials during classical conditioning of eyelid responses}

A total of 20 animals (i.e., Control-1 and Control-2 groups) (Fig. $1 B$ ) were classically conditioned using a trace (CS, tone; US, shock) paradigm (Fig. $2 A$ ). The time interval between the end of the CS and the beginning of the US was $500 \mathrm{~ms}$. The experimental design included the presentation of a single electrical pulse to Schaffer collaterals $300 \mathrm{~ms}$ after CS presentation. Figure $2 \mathrm{~A}$ shows single recordings of the EMG activity of the orbicularis oculi muscle and of the fEPSP evoked in a well trained animal during the seventh conditioning session. Although the stimuli presented to Schaffer collaterals disrupted the regular theta rhythm recorded in the local EEG for 100-200 ms, the rhythm reappeared in phase. As illustrated in Figure $2 B$, the learning curve presented by these conditioned animals was normal when compared with previous descriptions in mice, using similar trace conditioning procedures (Takatsuki et al., 2003; Domínguez-delToro et al., 2004). Animals presented a mean of $37 \pm 6 \%$ responses during the first conditioning session, and reached asymptotic values from the seventh session onward $(70-75 \%$ of conditioned responses). The mean percentage of conditioned responses collected for control animals was significantly larger $\left[F_{(18,162)}=192.7 ; p<0.001\right.$ for the 10 conditioning sessions compared with values reached by the pseudoconditioned group $(n=10)$ ] (Fig. $2 B)$.

Field EPSPs evoked in controls by the electrical stimulation of Schaffer collaterals increased progressively in slope (taking the slope of fEPSPs collected during the four habituation sessions as $100 \%$ ) across conditioning, to a maximum of $120 \%$ during the eighth and ninth sessions. During extinction, the fEPSP slope decreased to a minimum of $82.5 \%$ by the fifth session. In contrast, fEPSP values collected from the pseudoconditioned group did not present any tendency for a change in slope during either conditioning or extinction sessions. Values of fEPSP slopes for the control group were significantly different from those for pseudoconditioned animals for the 5th to the 10th conditioning and 3 rd to 5 th extinction sessions $\left(F_{(18,162)}=48.2 ; p<0.001\right)$.

As illustrated in Figure 3, the slope of fEPSPs evoked by Schaffer collateral stimulation at the CA3-CA1 synapse was linearly related ( $\mathrm{r} \geq 0.66 ; p<0.001$ ) to the percentage of conditioned responses across sessions of conditioning (slope, 0.55) and ex-
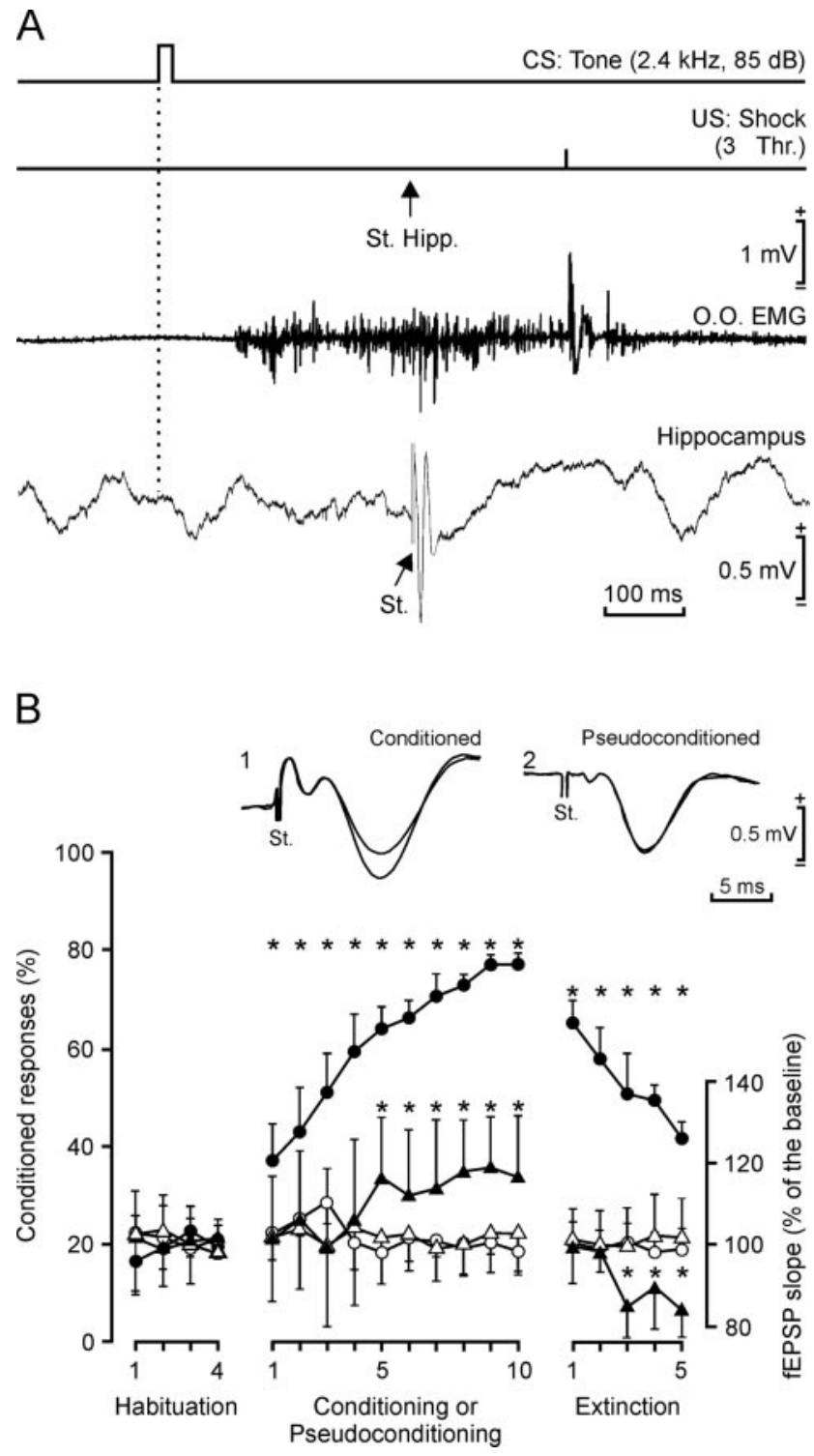

Figure 2. Learning curves and evolution of the synaptic field potential for control and pseudoconditioned groups. $\boldsymbol{A}, \mathrm{A}$ schematic representation of the conditioning paradigm, illustrating $C S$ and US stimuli, and the moment at which a single pulse (100 $\mu$ s; square; biphasic) was presented to Schaffer collaterals (St. Hipp.). An example of an EMG recording from the orbicularis oculi $(0.0$.) muscle obtained from the seventh conditioning session is illustrated, as well as an extracellular recording of hippocampal activity from the same animal, session, and trial. Note the fEPSP evoked by the single pulse presented to Schaffer collaterals. $\boldsymbol{B}$, At the top are illustrated fEPSPs recorded in the CA1 area after a single pulse presented to the ipsilateral Schaffer collaterals $300 \mathrm{~ms}$ after CS presentation, in a conditioned (1) and in a pseudoconditioned (2) animal, during the 1st and 10th conditioning sessions. The graphs at the bottom show the evolution of the percentage (\%) of CRs during the successive sessions for conditioned (control, filled circles) and pseudoconditioned (circles) groups. Mean percentage values are followed by \pm SD. Differences between conditioned and pseudoconditioned groups were statistically significant for all conditioning sessions $\left(F_{(18,162)}=192.7 ;{ }^{*} p<0.001\right)$. Evolution of the fEPSP slope is also indicated for conditioned (black triangles) and pseudoconditioned (open triangles) groups, expressed as the percentage change with respect to mean values collected during the four habituation sessions. Differences between conditioned and pseudoconditioned groups were statistically significant from the 5 th to the 10 th conditioning sessions and from the third to the fifth extinction sessions $\left(F_{(18,162)}=48.2 ;{ }^{*} p<0.001\right)$.

tinction (slope, 0.65), but not habituation. The fact that the slopes of the two regression lines were similar suggests that the activity-dependent plasticity at the CA3-CA1 synapse functioned as a continuum for both acquisition and extinction processes. 

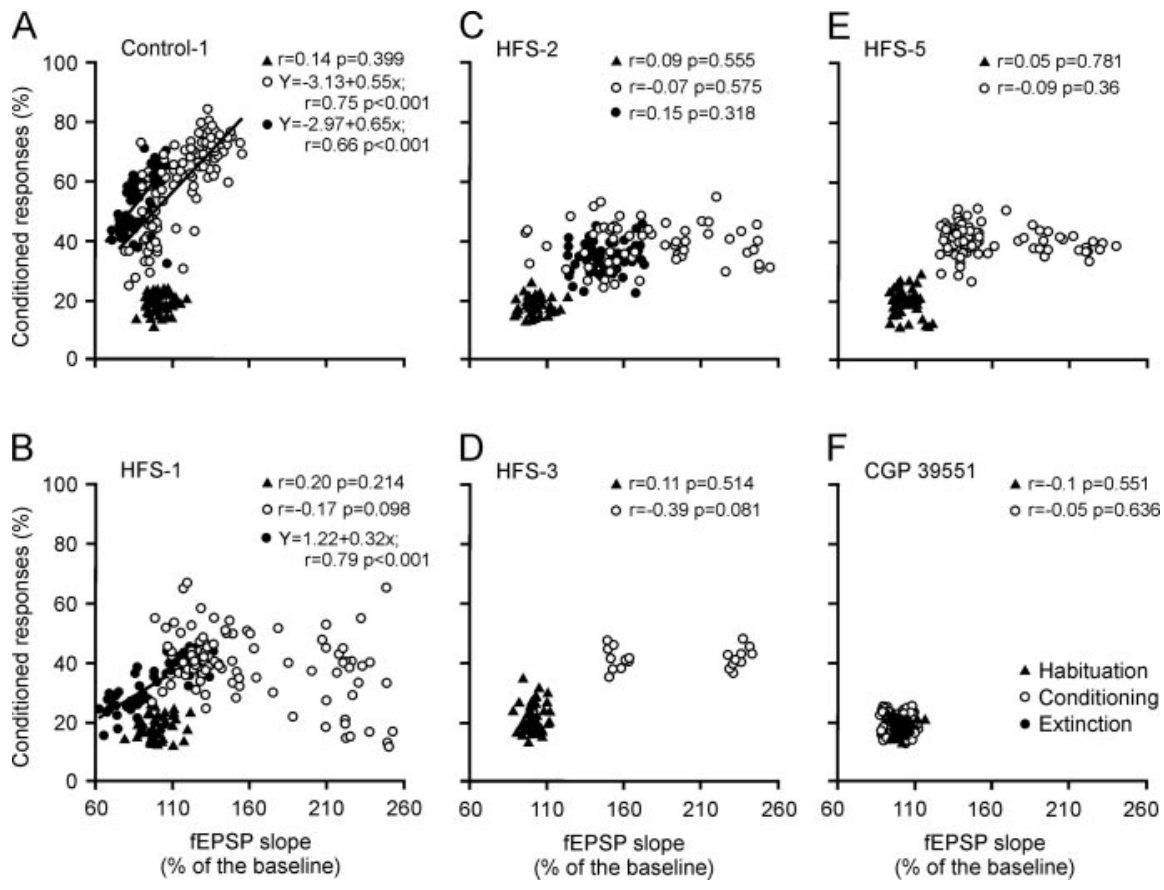

Figure 3. Quantitative analysis of the relationships between percentage of conditioned responses and fEPSP slopes for the different experimental groups during habituation, conditioning, reconditioning, and extinction sessions. $\boldsymbol{A}-\boldsymbol{F}$, Data collected from controls ( $\boldsymbol{A})$, HFS-1 (B), HFS-2 ( $\boldsymbol{C}$, HFS-3 (D), HFS-5 (E), and CGP $39551(\boldsymbol{F})$ groups. Each point represents the mean value collected from a single animal during the corresponding session. Data collected from habituation (black triangles), conditioning or reconditioning (open circles), and extinction (filled circles) sessions are illustrated. Represented data for conditioning and extinction sessions correspond exclusively to those collected after HFS sessions. Regression lines and their corresponding equations are included only for coefficients of correlation $(r>0.6)$. The $p$ values for each regression analysis are always indicated.
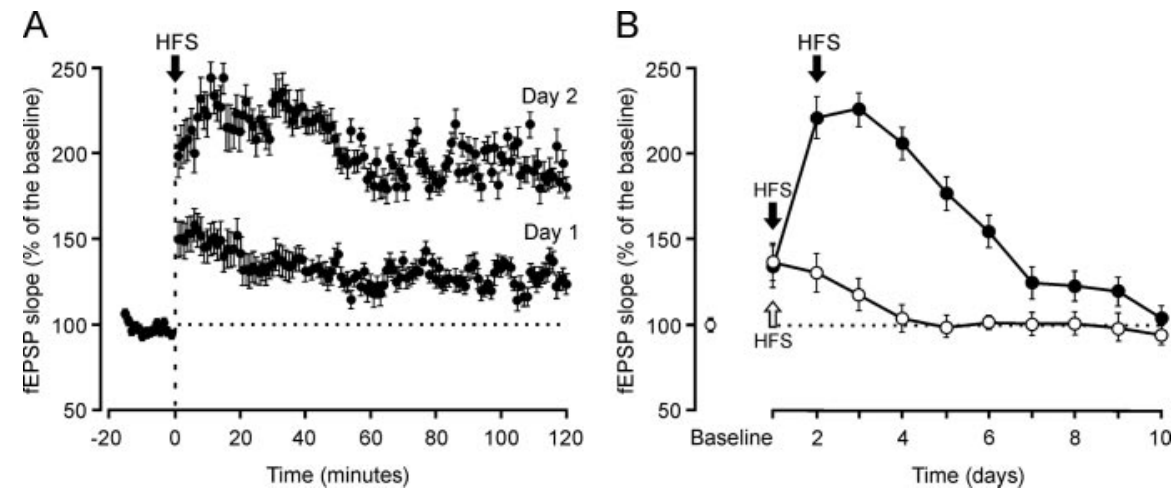

Figure 4. LTP induction in the CA1 area after electrical stimulation of the Schaffer collaterals. $\boldsymbol{A}$, LTP induction in the same animal. The HFS was presented for two consecutive days. The fEPSP is given as a percentage of the baseline (100\%) slope. To obtain a baseline, animals were stimulated every $5 \mathrm{~s}$ for $15 \mathrm{~min}$ at $\mathrm{Schaffer}$ collaterals. After HFS, the same stimulus was presented at the same rate (12 per $\mathrm{min}$ ) for $2 \mathrm{~h}$. B, LTP induction in two groups of animals ( $n=5$ each). One group of animals received HFS trains for only $1 \mathrm{~d}$ (open arrow and circles), whereas the other group was stimulated for $2 \mathrm{~d}$ (black arrows and filled circles). To check LTP evolution, animals were stimulated daily at $S$ chaffer collaterals every $5 \mathrm{~s}$ for 15 min. Values are expressed as mean \pm SD.

This interesting finding prompted us to hypothesize that evoking LTP experimentally at the CA3-CA1 synapse could interfere with the acquisition of associative learning using classically conditioned procedures.

\section{Evoking LTP in behaving mice}

In a pilot study, we evoked LTP in behaving mice $(n=5)$. To obtain a baseline, animals were stimulated every $5 \mathrm{~s}$ for $15 \mathrm{~min}$ at Schaffer collaterals. The stimulus consisted of a $100 \mu$ s, square, biphasic pulse. Pulse intensity (50-350 $\mu \mathrm{A})$ was set at $30-40 \%$ of the amount necessary to evoke a maximum fEPSP response. For evoking LTP, each animal was presented with five trains $(200 \mathrm{~Hz} ; 100$ $\mathrm{ms}$ ) of pulses at a rate of 1 per second. This protocol was presented six times in total, at intervals of $1 \mathrm{~min}$. To avoid evoking a population spike and/or unwanted EEG seizures, the stimulus intensity was set at the same amount used for generating the baseline recording. After HFS, the same single stimulus was presented at the initial rate (12 per minute) for another $15 \mathrm{~min}$. As illustrated in Figure $4 B$, with this experimental approach we were able to evoke LTPs lasting $4 \mathrm{~d}$. In accordance, and to obtain LTPs lasting as long as the conditioning sessions (i.e., $\approx 10 \mathrm{~d}$ ), in an additional pilot study ( $n=5$ animals), we used the same procedure for evoking LTP, but this time the HFS protocol was presented for two successive days. As illustrated in Figure $4 A$ and $B$, this procedure evoked LTP (with above-baseline values) that lasted up to $10 \mathrm{~d}$.

\section{Evolution of CA3-CA1 synaptic field potentials and acquisition of conditioned eyelid responses after LTP induction}

As illustrated in Figure $1 B$, we prepared five experimental groups (HFS-1 to HFS-5) to be conditioned as indicated for controls, but which received two HFS sessions $30 \mathrm{~min}$ before the first and second (HFS-1), fifth and sixth (HFS-2), or ninth and 10th (HFS-3) conditioning days, during two recall sessions (HFS-4), or during the first and second reconditioning sessions (HFS-5).

As shown in Figure 5A, HFS applied during the first two conditioning sessions (HFS-1 group; $n=10$ ) produced a noticeable LTP that remained above baseline values for up to $9 \mathrm{~d}\left(F_{(18,162)}=32.8 ; p<\right.$ 0.001 ). Animals of this group were unable to present a normal learning curve. In fact, the second HFS produced a noticeable decrease in the percentage of conditioned responses (Fig. 5B). Along conditioning, the percentage of learned responses remained $\left.F_{(18,162)}=15 ; p<0.001\right)$. HFS- 1 animals presented a definite extinction of conditioned responses in simultaneity with a decrease (as in controls) of the fEPSP slope during the extinction sessions. In accordance, fEPSP slopes and the percentage of conditioned responses were not linearly related for HFS- 1 animals during the ten conditioning sessions (Fig. 3B); however, the same parameters collected during the five extinction sessions showed a statistically significant linear relationship $(r=0.79 ; p<0.001)$.

Animals $(n=10)$ of the HFS-2 group received the two HFS sessions 30 min before the fifth and sixth conditioning sessions 
(Fig. $5 C, D$ ). In this case, the slope of the fEPSP remained above baseline values for the 6 th to the 10th conditioning sessions and during the five extinction sessions $\left(F_{(14,126)}=7.58 ; p<0.001\right)$. These animals presented a gradually increasing learning curve up to the day before HFS presentation $52.5 \%$ of conditioned responses by the fourth conditioning session; $\left.F_{(14,126)}=43.2 ; p<0.001\right)($ Fig. $5 D)$. However, the two HFS sessions decreased the number of conditioned responses to values $<40 \%$ from the 5 th to the 10 th conditioned sessions. Interestingly, these animals were unable to extinguish the acquired level of conditioning, probably because extinction sessions took place during the presence of a significant LTP. In accordance, no linear relationship between fEPSP slopes and the percentage of conditioned responses across conditioning and extinction sessions was observed for the HFS-2 group (Fig. 3C).

Animals $(n=10)$ of the HFS-3 group received the two HFS sessions during the last $2 \mathrm{~d}$ of conditioning (Fig. 6A,B). The HFS provoked an LTP that was still evident during the two recall sessions (i.e., it lasted at least $11 \mathrm{~d} ; F_{(7,63)}=16.8 ; p<$ 0.001). LTP induction evoked a significant decrease in the learning curve achieved by these animals (Fig. 6B). The percentage of conditioned responses during recall was increased with respect to the last two conditioning sessions, during which the HFS protocol was presented $\left(F_{(7,63)}=162.4\right.$; $p<0.001)$. No linear relationship between fEPSP slope and the percentage of conditioned responses across conditioning and recall sessions was observed for the HFS-3 group (Fig. 3D).

In contrast to results collected from the HFS-3 group, those from animals $(n=10)$ of the HFS-4 group (Fig. $6 C, D)$, which received the two HFS sessions during recall, showed a significantly $\left(F_{(5,45)}=16.9 ; p<0.001\right)$ lower percentage of conditioned responses than those obtained during the last two conditioning sessions. In this situation, it was of interest to determine the retention index [i.e., the ratio between the mean percentage of condition responses (CRs) during the last two conditioning sessions and the two recall sessions] for controls (Control-2 group) and for the HFS-3 and HFS-4 groups (Fig. 6E). The retention index for the HFS-4 group $(0.69 \pm 0.11)$ was significantly lower $(p \leq 0.01)$ than that collected from controls $(1.09 \pm 0.2)$ and from the HFS-3 group $(1.32 \pm 0.2)$. These results suggest that the recall of an earlier experience is a rather unstable situation, susceptible to being blocked by LTP evoked experimentally at the CA3-CA1 synapse. Nevertheless, and according to the present data, the effects of evoking LTP during classical conditioning were greater when evoked in the presence of a large percentage of conditioned responses (i.e., $+10 \%$ for the HFS-1 group, $-20 \%$ for the HFS-2 group, $-29 \%$ for the HFS-3 group, $-28.5 \%$ for the HFS -4 group, and $+14.5 \%$ for the HFS-5 group).

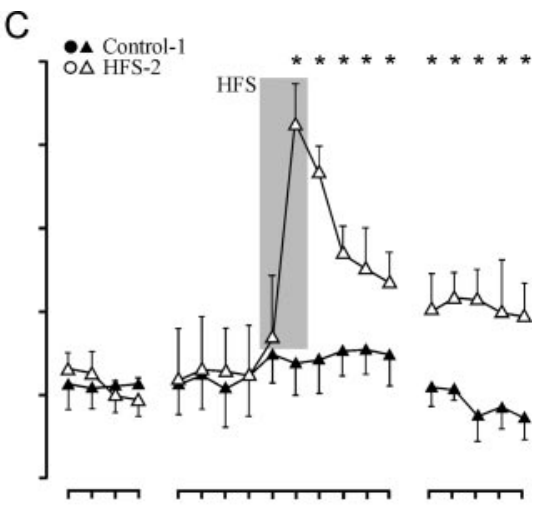

D

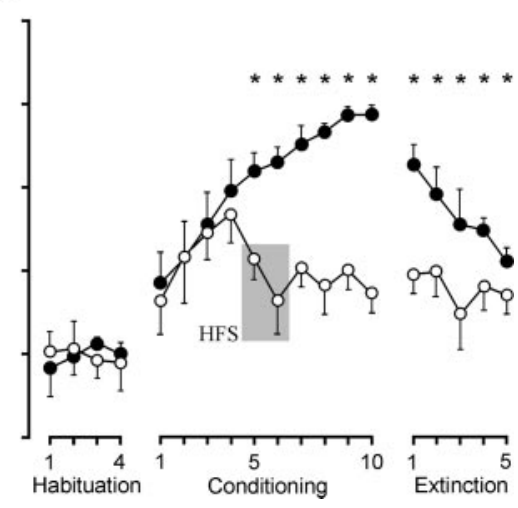

Figure 5. Learning curves and evolution of the synaptic field potential for controls and groups HFS-1 and HFS-2. A, B, fEPSP slope ( $\boldsymbol{A}$, open triangles) and percentage ( $\boldsymbol{B}$, circles) of conditioned responses from animals receiving HFS (gray lane) before the (A) conditioning sessions (HFS-1 group). For comparative purposes, data collected from the control group are also indicated HES-1 roup was significantly cquisition and extinction curves presented by the HFS-1 group were also significantly different from those of controls $\left(F_{(18,162)}=\right.$ , $>0.001) . \boldsymbol{C}, \boldsymbol{D}$, fEPSP slope ( $\boldsymbol{C}$, open triangles) and percentage $(\boldsymbol{D}$, circles) of conditioned responses from animals receiving 作 baseline values (100\%) during the last 5 dof conditioning $F(4,120=7.58 * 0<0.001)$. From the two HFS sessions onward acquisition (and extinction) curves presented by the HFS-2 group were significantly $\left(F_{(14,126)}=43.2 ;{ }^{*} p<0.001\right.$ ) different from those of controls. Values are expressed as mean \pm SD.

Evolution of CA3-CA1 synaptic field potentials and acquisition of conditioned eyelid responses during reconditioning for controls and after LTP induction

Figure 7 represents data collected from the Control-1 group $(n=$ 10 ; i.e., from control animals that received 10 reconditioning sessions), and from the HFS-5 group ( $n=10$; i.e., from animals that received the two HFS sessions during the first $2 \mathrm{~d}$ of reconditioning). During the $10 \mathrm{~d}$ of reconditioning, HFS-5 animals were unable to exceed values reached during the last extinction session, indicating that the evoked LTP completely blocked the possibility of reacquiring eyelid conditioned responses, in contrast to the case of controls. Thus, the percentage of conditioned responses presented by animals from the HFS-5 group for the 10 conditioning sessions was significantly lower than that achieved by controls $\left(F_{(13,117)}=207.4 ; p<0.001\right)$. The slope of fEPSPs evoked in the CA1 area by Schaffer collateral stimulation increased steadily in controls across reconditioning sessions (Fig. $7 A$ ), reaching a maximum (128.3\%) above baseline values (100\%) during the 10th conditioning session. In contrast, the slope of fEPSPs evoked in HFS-5 animals was clearly dominated by the effect of the induced LTP, with no sign of modulation by (or during) the acquisition process (Figure $7 A)\left(F_{(13,117)}=6.09\right.$; 


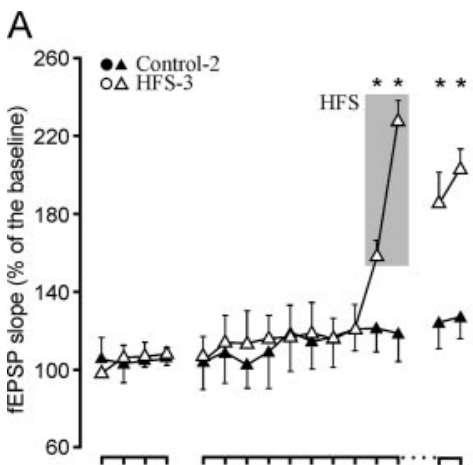

B

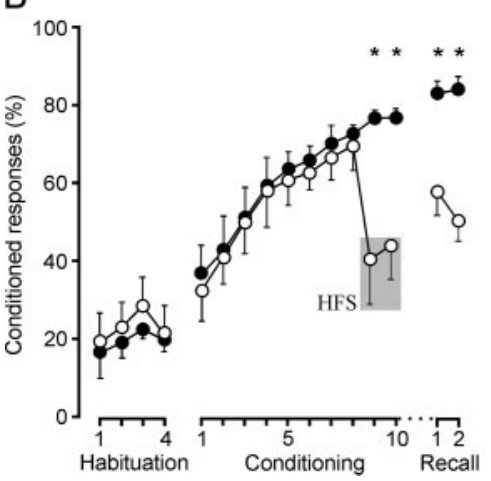

C

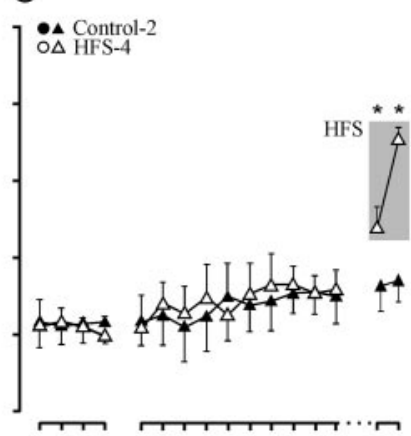

$\mathrm{D}$

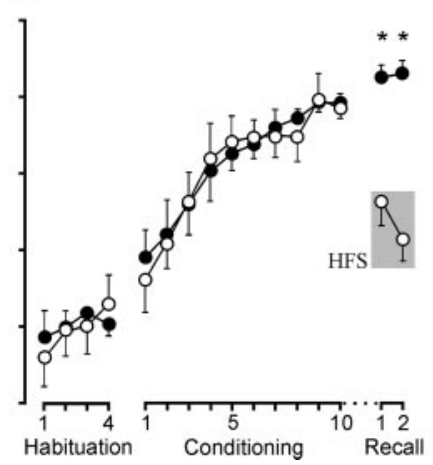

E

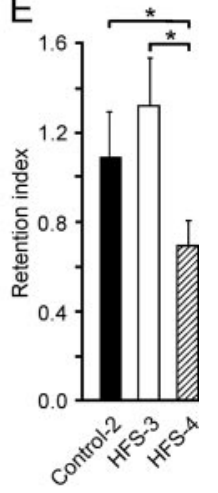

Figure 6. Learning curves and evolution of the synaptic field potential for controls and groups HFS-3 and HFS-4. A, B, fEPSP slope ( $\boldsymbol{A}$, open triangles) and percentage ( $\boldsymbol{B}$, circles) of conditioned responses from animals receiving HFS (gray lane) before the last two conditioning sessions (HFS-3 group). For comparative purposes, data collected from the control group are also indicated ( $\boldsymbol{A}$, fEPSP, black triangles; $\boldsymbol{B}$, percentage of responses, filled circles). As a result of the LTP evoked by HFS, the fEPSP slope for the HFS-3 group was significantly larger than baseline values during the last $2 \mathrm{~d}$ of conditioning and the two recall sessions $\left(F_{(7,63)}=\right.$ $\left.16.8 ;{ }^{*} p<0.001\right)$. After the two HFS sessions, the learning curves presented by the HFS-3 group were significantly $\left(F_{(7,63)}=\right.$ $\left.162.4 ;{ }^{*} p<0.001\right)$ different from those of controls. $\boldsymbol{C}, \boldsymbol{D}$, fEPSP slope ( $\boldsymbol{C}$, open triangles) and percentage ( $\boldsymbol{D}$, circles) of conditioned responses from animals receiving HFS (gray lane) before the two recall sessions (HFS-4 group), compared with controls (C, EEPSP, black triangles; $\boldsymbol{D}$, percentage of responses, filled circles). As a result of the LTP evoked by HFS, the fEPSP slope was significantly larger than baseline values during the two recall sessions $\left(F_{(5,45)}=8.37 ;{ }^{*} p<0.001\right)$. In addition, the learning curves presented by the HFS-4 group were significantly $\left(F_{(5,45)}=16.9 ;{ }^{*} p<0.001\right)$ different from those of controls during the two recall sessions. $\boldsymbol{E}$, Retention index for controls and HFS-3 and HFS-4 groups. The retention index represents the ratio between the mean percentage of CRs during the last two conditioning sessions and the two recall sessions. The retention index was significantly lower for the HFS-4 group as compared with controls and the HFS-3 group ( $\left.{ }^{*} p \leq 0.01\right)$. Values are expressed as mean \pm SD.

Involvement of NMDA channels in the acquisition of trace conditioning Although the involvement of AMPA and NMDA receptors in LTP phenomena evoked at the CA3-CA1 synapse is well known (Collingridge et al., 1983a,b; Bliss and Collingridge, 1993), an attempt was made at a precise determination of the relationships between LTP, NMDA receptors, and the acquisition of associative learning using a trace classical conditioning paradigm. As illustrated in Figure $8 \mathrm{~A}$, the administration of NBQX (a selective and competitive antagonist of the AMPA receptor; $15 \mathrm{mg} / \mathrm{kg}$, i.p.; $n=5$ ) significantly decreased (by some $40 \% ; p<0.01$ ) the slope of fEPSPs evoked in the CA1 area by single pulses applied to Schaffer collaterals, whereas the addition of CGP 39551 (a selective and competitive NMDA receptor antagonist; $6.5 \mathrm{mg} / \mathrm{kg}$, i.p.; $n=5$ ) had no additional effect, indicating that the contribution of the NMDA receptor to the fEPSP was almost negligible in this situation (Harris et al., 1984). However, and as illustrated in Figure $8 B$, HFS of Schaffer collaterals was unable to evoke an LTP in the CA3-CA1 synapse in the presence of CGP $39551(6.5 \mathrm{mg} / \mathrm{kg}$, i.p.; $n=5)$ as compared with controls $(n=5)$.

In an additional experiment, animals (CGP 39551 group; $n=10$ ) were conditioned after the daily injection of CGP 39551 (6.5 mg/kg, i.p., 30 min before each conditioning session). Field EPSPs evoked in the CA1 area by the electrical stimulation of Schaffer collaterals were not modified in slope across conditioning sessions in the CGP 39551 group (Fig. 8C, second set of recordings) as compared with controls (Fig. 8C, first set of recordings). Significantly, animals from the CGP 39551 group did not present any evidence of eyelid conditioned responses, as illustrated by

$p<0.001)$. In this regard, no linear relationship between fEPSP slopes and the percentage of conditioned responses across reconditioning sessions was observed for the HFS- 5 group (Fig. 3E).

It is important to point out that the learning deficits described here were the effect of LTP induction and not of the HFS by itself. Thus, some mice ( $n=17$ initially included in groups HFS- 1 to HFS-5) received the two HFS sessions, but no significant potentiation ( $<20 \%$ increase in fEPSP slope, lasting $<30 \mathrm{~min}$ ) was observed in them. Data collected from these animals were not included in the analysis for groups HFS-1 to HFS-5, but were used to determine whether the deficits in associative learning were caused by the HFS or the evoked LTP. Indeed, all of these animals presented acquisition curves $\left(F_{(18,162)}=175.6 ; p=0.23\right)$ and fEPSP slopes $\left(F_{(18,162)}=68 ; p=0.41\right)$ nonsignificantly different from those shown by controls (Fig. 7C,D). In accordance, the learning deficits described in this and the preceding sections cannot be ascribed to any damage of hippocampal circuits produced by the HFS, but to the proper induction of LTP. the two recordings from the eighth session collected from a control and from a CGP 39551-injected animal (Fig. 8D). Finally, Figure $8 E$ illustrates the evolution of conditioned responses and of the slope of fEPSPs collected across conditioning from the CGP 39551 group. The percentage of conditioned responses in the control group was significantly larger than that in the CGP 39551 group from the 2 nd to the 10th conditioning sessions $\left(F_{(13,117)}=235.6 ; p<0.001\right)$. Moreover, fEPSP slopes were significantly larger in controls than in the CGP 39551 group for the last four conditioning sessions $\left(F_{(13,117)}=45.9 ; p<0.001\right)$.

\section{Discussion}

\section{General remarks}

We have shown here that the hippocampal CA3-CA1 synapse is involved in the acquisition, extinction, recall, and reconditioning of eyelid CRs using a trace paradigm. These synaptic elements underwent a slow potentiation, or decrease, in synaptic strength (Hebb, 1949) in parallel with the acquisition and/or extinction of eyeblink conditioning. We have also shown that LTP, evoked by 
HFS of Schaffer collaterals, interferes with both the acquisition of CRs and the linear relationships between learning scores and fEPSP slopes. The saturation of the CA3CA1 synapse by LTP, at different stages across conditioning, prevented additional synaptic changes in plasticity (Barnes et al., 1994; Otnæss et al., 1999), causing both anterograde and retrograde amnesia. This experimental disturbance of the hippocampal pattern of synaptic strengths is apparently enough to interfere with the functional states necessary for the proper acquisition, storage, and retrieval of eyeblink conditioning, as already demonstrated for spatial learning (Barnes et al., 1994; Brun et al., 2001). Finally, we showed that the administration of an NMDA-receptor antagonist is not only able to prevent LTP induction in vivo, but also to hinder both the formation of eyelid CRs and the functional changes in strength at the CA3-CA1 synapse. Thus, the functional transformations taking place at CA1 pyramidal cells seem to be necessary for the proper acquisition, extinction, recall, and reconditioning of eyelid CRs.

\section{Modulation in the synaptic strength of the CA3-CA1 synapse during trace conditioning}

In a seminal study, Weisz et al. (1984) demonstrated a change in the efficacy of synaptic activation of dentate granule cells by perforant pathway axons during the acquisition of nictitating membrane CRs. This modulation in synaptic strength during the learning process has been confirmed here for the CA3-CA1 synapse, and it has been extended to the extinction process, suggesting that the two phenomena are equally active (Inda et al., 2005) and require an activitydependent modification of synaptic responsivity for learning to occur (Weisz et al., 1984). Moreover, it has also been shown that the evoked changes in synaptic efficacy present a linear relationship with the amount of acquired, or extinguished, learning. The increase in fEPSP slope during the acquisition process explains the increased firing in hippocampal CA1 areas across conditioning, described for both rabbits and cats (McEchron et al., 2003; Múnera et al., 2001).

The involvement of hippocampal unitary activity in classical conditioning of the nictitating membrane/eyelid response is very well known (Berger et al., 1983; Moyer et al., 1990). For example, it has been shown, using unitary in vivo recordings (McEchron and Disterhoft, 1997), that hippocampal pyramidal cell firing to CS presentation increases several sessions in advance of behavioral conditioning. Although the discharge rate of hippocampal CA1 pyramidal neurons does not seem to encode the kinetic peculiarities of conditioned eyelid responses, it has been shown that CA1 firing is linearly related with the progressive acquisition of the eyelid learned response, with a gain of $\approx 0.035$ spikes per second per trial, as measured in behaving cats during trace (toneshock) conditioning (Múnera et al., 2001). Interestingly, this slow building up of hippocampal neuronal responses across con-
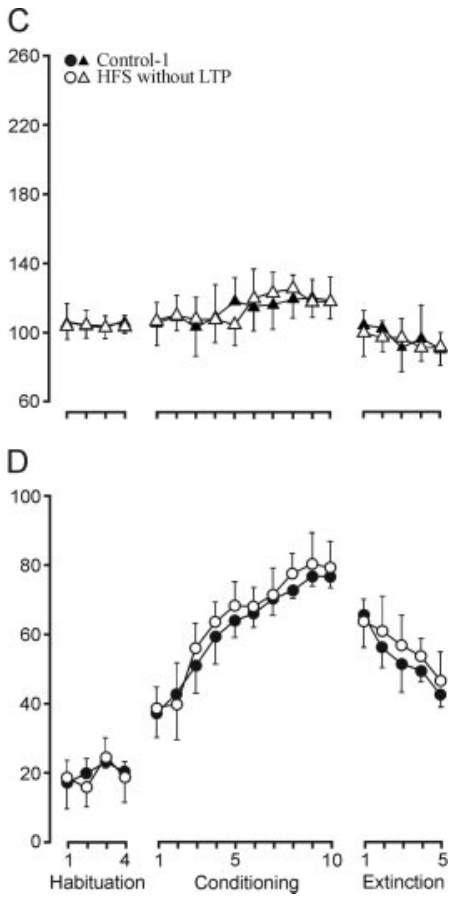

Figure 7. Learning curves and evolution of the synaptic field potential for controls, group HFS-5, and animals unable to evoke P after two sessions of HFS. $\boldsymbol{A}, \boldsymbol{B}$, fEPSP slope ( $\boldsymbol{A}$, open triangles) and percentage ( $\boldsymbol{B}$, circles) of conditioned responses from (gray lane) before the last two reconditioning sessions (HFS-5 group). For comparative purposes, data significantly $\left(F_{(13,117)}=207.4{ }^{*} p<0.001\right)$ different from those of controls during the 10 conditioning sessions. C, D, fEPSP slope circles). Note that these HFS animals presented acquisition curves $\left(F_{(18,162)}=175.6 ;{ }^{*} p=0.23\right)$ and fEPSP slopes $\left(F_{(18,162)}=68\right.$; ditioning is similar to the small increase in the slope of the fEPSP evoked at the apical dendrite of CA1 pyramidal cells by single pulses applied to Schaffer collaterals (i.e., a $0.03 \%$ increase in fEPSP slope/trial) reported here. It appears that fEPSP slopes reached an asymptotic value during the last conditioning sessions, in parallel with the evolution in the percentage of CRs. Because only five extinction sessions were performed here, similar observation has not been made during the extinction process. Nevertheless, the two phenomena presented linear regression lines of the same slope when plotted versus the amount of CRs, suggesting that the modulation in synaptic strength is similar for both processes, moving in the increasing (or decreasing) direction depending on the learning situation.

The modulation in CA3-CA1 synaptic strength reported here during acquisition, extinction, recall, and reconditioning seems to be a slow process originated by changes in the probability of releasing synaptic vesicles by CA3 terminals and/or by subtle modifications in the number of presynaptic active zones and/or postsynaptic receptor sites (Bolshakov et al., 1997) (i.e., by synaptic plastic changes also related to LTP) (Nicoll, 2003). From a functional point of view, the increased (or decreased) responsivity of CA1 pyramidal cells to Schaffer collateral stimulation suggests that, during the CS-US interval, they are in a facilitated (or disfacilitated) state, evoked by changes in coincident inputs of different (entorhinal, septal, etc.) origins (Weisz et al., 1984; Fontán-Lozano et al., 2005). Thus, it is possible that several mechanisms are acting in parallel to enhance CA3-CA1 synaptic 
A
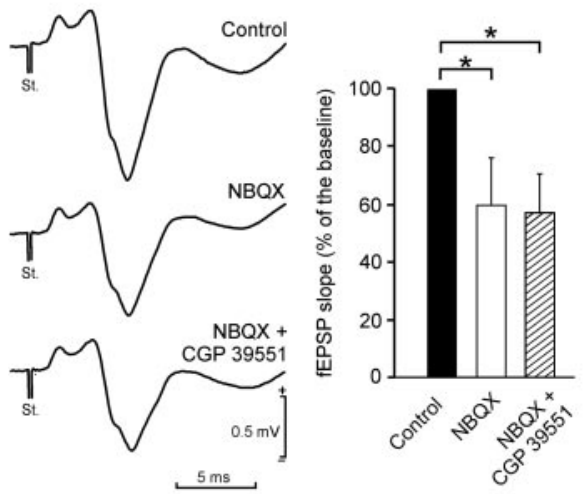

C
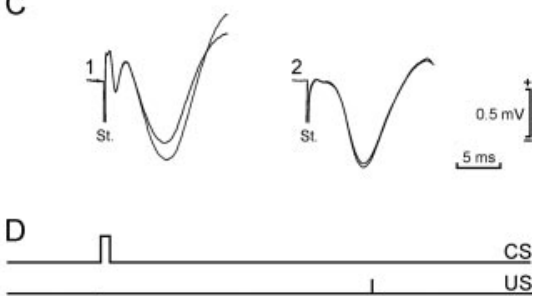

B

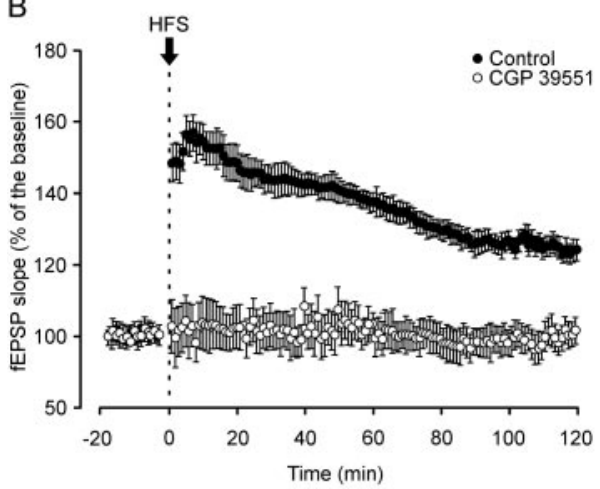

E

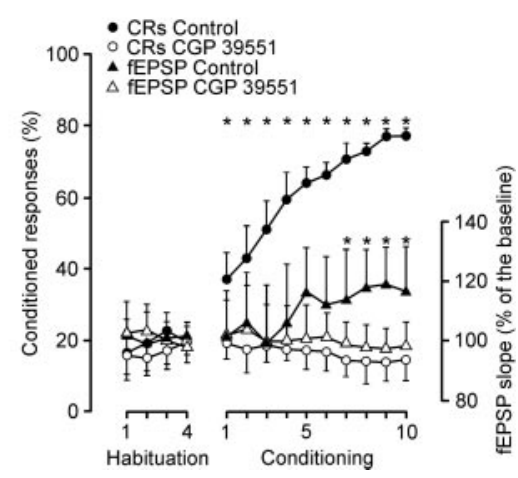

Figure 8. NBQX (an AMPA antagonist) reduces the fEPSP slope evoked at the CA1 area by a single pulse applied to the ipsilateral Schaffer collateral, whereas CGP 39551 (an NMDA antagonist) blocks LTP and classical conditioning. $\boldsymbol{A}$, At the top is shown an averaged fEPSP ( $n=5$ sweeps) evoked in the CA1 area by a single pulse presented to ipsilateral Schaffer collaterals, and recordings collected 30 min after NBQX (middle, 15 mg/kg, i.p.), and NBQX (15 mg/kg, i.p.) plus CGP 39551 (bottom, $6.5 \mathrm{mg} / \mathrm{kg}$, i.p.). The histogram to the right illustrates that NBQX reduced the slope of the evoked fEPSP by some $40 \%$, but that the addition of CGP 39551 had no additional effect. $\boldsymbol{B}$, LTP evoked in controls $(n=5)$ and in animals injected with CGP 39551 (6.5 mg/kg; 60 min before HFS). $C$, fEPSPs recorded in the (A1 area after a single pulse presented to the ipsilateral Schaffer collaterals $300 \mathrm{~ms}$ after CS presentation in a control animal (1) and in a CGP 39551-injected animal (2) during the first and eighth conditioning sessions. D, Comparison of conditioned responses [EMG activity of the orbicularis oculi muscle $(0.0$.$) ] recorded during the eighth conditioning$ session in a control and in a CGP 39551-injected animal, respectively. Note that the CGP 39551-injected animal responded normally to US presentation. The conditioning paradigm is illustrated at the top. $E$, Learning curves and evolution of the synaptic field potential for controls and for the CGP 39551 group. The CGP 39551 group of animals was injected 30 min before each conditioning session (6.5 mg/kg, i.p.). Differences in conditioned responses between control (filled circles) and CGP 39551 (open circles) groups were statistically significant from the 2 nd to the 10 th conditioning sessions $\left(F_{(13,117)}=235.6 ;{ }^{*} p<0.001\right)$. Evolution of the EEPSP slope is also indicated for control (black triangles) and CGP 39551 (open triangles) groups, expressed as the percentage change to mean values collected during the four habituation sessions. Differences between control and CGP 39551 groups were statistically significant from the 6 th to the 10th conditioning sessions $\left(F_{(13,117)}=45.9 ;{ }^{*} p<0.01\right)$. Values are expressed as mean $\pm S D$.

transmission across learning. In any case, the plastic changes in synaptic strength evoked during the learning process are noticeably much smaller (in volts per second of the fEPSP) and slower (in time) than those evoked by the experimentally induced LTP (i.e., the two phenomena have a quite different time scale).

\section{Anterograde and retrograde amnesia evoked by experimentally induced LTP}

Humans with hippocampal lesions present both anterograde and (immediate) retrograde amnesia (Squire and Alvarez, 1995). Indeed, it has been shown that spatial learning is prevented when saturating LTP is evoked in the perforant pathway or when evoked by the repeated stimulation of a large number of hippocampal synaptic contacts (McNaughton et al., 1986; Casto et al., 1989; Moser et al., 1998; Dragoi et al., 2003). The effects of
LTP evoked at the hippocampus are more evident for the acquisition of new learning skills and on recently acquired knowledge, but not for remote memory retrieval (Morris et al., 2003). Present results essentially confirm those findings, but using trace conditioning (i.e., a task which requires the active participation of hippocampal circuits) (Thompson, 1988).

It has been reported that, for spatial learning, pretraining prevents the deficits evoked by LTP (Otnæss et al., 1999), a fact not confirmed here for trace conditioning. In fact, the retrograde deficits were more evident with additional training, because, in all cases (Figs. 5-7), the amount of evoked CRs decreased to the same level $(\approx 40 \%)$ after LTP. Perhaps relational learning is more dependent on the functional state of hippocampal circuits than is spatial learning. It is still possible that this $40 \%$ of residual learning is hippocampally independent (i.e., acquired by subcortical and/or cerebellar circuits).

The present results show that when LTP values returned to baseline physiological values (i.e., 100-120\% from baseline fEPSP) (Fig. 7 $A, B$ ) learning did not recover. This may indicate that the induction of LTP through high frequency stimulation resulted in a permanent physiological disruption which produced both anterograde and retrograde memory deficits.

According to the present results, the retention index during recall plus HFS (HFS-4 group) was lower than in controls, or even in the group (HFS-3) that received HFS $7 \mathrm{~d}$ before the two recall sessions. In this regard, it has been reported that electroconvulsive shock or systemic drug administration given after memory reactivation might produce a severe amnesia for the original learning (Nader et al., 2000; Sara, 2000; Nader, 2003; Inda et al., 2005). These results indicate that recent memories become somewhat labile when they are recalled; thus, they require a proper reconsolidation, which is blocked in the HFS-4 group by the simultaneous presentation of the two HFS sessions. Thus, hippocampal firing seems to be necessary during conditioning paradigms in which conscious knowledge is required, namely, for trace paradigms (Clark and Squire, 1998). These findings suggest that the hippocampus is perhaps not necessary after memory consolidation (Squire and Alvarez, 1995; Morris et al., 2003).

Relationships between LTP, NMDA channels, and functional modifications of synaptic strength

The generation of CRs is a slow process requiring a large number $(<300)$ of paired CS-US presentations in mice, rabbits, and cats (Thompson, 1988). Thus, the neural processes underlying its generation cannot be directly related to LTP mechanisms, by which an almost immediate acquisition of the learned response is 
expected (Ito, 1989; Bliss and Collingridge, 1993). The motor output expected from associative learning is not a sharp, sustained increase in neuronal firing of a pool of related neural centers, but a distributed and limited increase in the number of neurons recruited to respond to an initially irrelevant sensory stimulus (i.e., the CS) (Woody, 1986). But LTP has the property of associability, indicating that a weak input can still be potentiated if activated simultaneously to (or within a given time window of) a strong stimulus evoked through a separate but convergent input (McNaughton et al., 1978; Levy and Steward, 1983; Bliss and Collingridge, 1993).

However, it is known that hippocampal NMDA receptors are involved in the acquisition of eyelid CRs (Kishimoto et al., 2001; Sanders and Fanselow, 2003; Mokin and Keifer, 2005). As confirmed here, the administration of CGP 39551, a competitive antagonist of the NMDA receptor (Maren et al., 1992; Servatius and Shors, 1996; D'Hooge et al., 1999), prevents the acquisition of an eyeblink conditioning and also blocked the fEPSP potentiation observed in controls across learning. CGP 39551 also prevented the induction of LTP in the hippocampal CA1 area after HFS of Schaffer collaterals (Maren et al., 1992), but had no noticeable effects on the monosynaptic fEPSP evoked in the CA1 area by single pulses presented to the ipsilateral Schaffer collaterals. In contrast, the fEPSP evoked in CA1 was attenuated by NBQX, a selective and competitive AMPA-receptor antagonist (Parada et al., 1992; Namba et al., 1994), indicating that CA3CA1 synapses are normally activated by the opening of AMPA channels.

\section{References}

Barnes CA, Jung MW, McNaughton BL, Korol DL, Andreasson K, Worley PF (1994) LTP saturation and spatial learning disruption: effects of task variables and saturation levels. J Neurosci 14:5793-5806.

Berger TW, Rinaldi P, Weisz DJ, Thompson RF (1983) Single-unit analysis of different hippocampal cell types during classical conditioning of rabbit nictitating membrane response. J Neurophysiol 50:1197-1219.

Bliss TVP, Collingridge GL (1993) A synaptic model of memory: long-term potentiation in the hippocampus. Nature 361:31-39.

Bliss TVP, Gardner-Medwin AR (1973) Long-lasting potentiation of synaptic transmission in the dentate area of the unanaesthetized rabbit following stimulation of the perforant path. J Physiol (Lond) 232:357-374.

Bliss TVP, Lømo T (1973) Long-lasting potentiation of synaptic transmission in the dentate area of the anaesthetized rabbit following stimulation of the perforant path. J Physiol (Lond) 232:331-356.

Bolshakov VY, Golan H, Kandel ER, Siegelbaum SA (1997) Recruitement of new sites of synaptic transmission during the cAMP-dependent late phase of LTP at CA3-CA1 synapses in the hippocampus. Neuron 19:635-651.

Brun VH, Ytterbø K, Morris RGM, Moser MB, Moser EI (2001) Retrograde amnesia for spatial memory induced by NMDA receptor-mediated longterm potentiation. J Neurosci 21:356-362.

Casto CA, Silbert LH, McNaughton BL, Barnes CA (1989) Recovery of spatial learning deficits after decay of electrically induced synaptic enhancement in the hippocampus. Nature 342:545-548.

Clark RE, Squire LR (1998) Classical conditioning and brain systems: the role of awareness. Science 280:77-81.

Collingridge GL, Kehl SJ, McLennan H (1983a) The antagonism of amino acid-induced excitations of rat hippocampal CA1 neurones in vitro. J Physiol (Lond) 334:19-31.

Collingridge GL, Kehl SJ, McLennan H (1983b) Excitatory amino acids in synaptic transmission in the Schaffer collateral-commissural pathway of the rat hippocampus. J Physiol (Lond) 334:33-46.

D’Hooge R, Raes A, Van de Vijver G, Van Bogaert PP, De Deyn PP (1999) Effects of competitive NMDA receptor antagonists on excitatory amino acid-evoked currents in mouse spinal cord neurones. Fundam Clin Pharmacol 13:67-74.

Domínguez-del-Toro E, Rodríguez-Moreno A, Porras-García E, SánchezCampusano R, Blanchard V, Lavilla M, Böhme GA, Benavides J, DelgadoGarcía JM (2004) An in vitro and in vivo study of early deficits in asso- ciative learning in transgenic mice that over-express a mutant form of human APP associated with Alzheimer's disease. Eur J Neurosci 20:1945-1952.

Dragoi G, Harris KD, Buzsáki G (2003) Place representation within hippocampal networks is modified by long-term potentiation. Neuron 39:843-853.

Eichenbaum H (1999) Conscious awareness, memory and the hippocampus. Nat Neurosci 2:775-776.

Engert F, Bonhoeffer T (1999) Dendritic spine changes associated with hippocampal long-term synaptic plasticity. Nature 399:66-70.

Fontán-Lozano A, Troncoso J, Múnera A, Carrión AM, Delgado-García JM (2005) Cholinergic septo-hippocampal innervation is required for eyeblink classical conditioning. Learn Mem 12:557-563.

Gruart A, Blázquez P, Delgado-García JM (1995) Kinematics of unconditioned and conditioned eyelid movements in the alert cat. J Neurophysiol $74: 226-248$.

Gruart A, Pastor AM, Armengol JA, Delgado-García JM (1997) Involvement of cerebellar cortex and nuclei in the genesis and control of unconditioned and conditioned eyelid motor responses. Prog Brain Res 114:511-528.

Gruart A, Schreurs BG, Domínguez-del-Toro E, Delgado-García JM (2000) Kinetic and frequency-domain properties of reflex and conditioned eyelid responses in the rabbit. J Neurophysiol 83:836-852.

Gureviciene I, Ikonen S, Gurevicius K, Sarkaki A, van Groen T, Pussinen R, Ylinen A, Tanila H (2004) Normal induction but accelerated decay of LTP in APP + PS1 transgenic mice. Neurobiol Dis 15:188-195.

Harris EW, Ganong AH, Cotman CW (1984) Long-term potentiation in the hippocampus involves activation of $N$-methyl-D-aspartate receptors. Brain Res 323:132-137.

Hebb DO (1949) The organization of behavior. New York: Wiley.

Inda MC, Delgado-García JM, Carrion AM (2005) Acquisition, consolidation, reconsolidation, and extinction of eyelid conditioning responses require de novo protein synthesis. J Neurosci 25:2070-2080.

Ito M (1989) Long-term depression. Annu Rev Neurosci 12:85-102.

Kishimoto Y, Kawahara S, Mori H, Mishima M, Kirino Y (2001) Long-trace interval eyeblink conditioning is impaired in mutant mice lacking the NMDA receptor subunit $\epsilon 1$. Eur J Neurosci 13:1221-1227.

Kugelberg E (1952) Facial reflexes. Brain 75:385-396.

Levy WB, Steward O (1983) Temporal contiguity requirements for longterm associative potentiation/depression in the hippocampus. Neuroscience 8:791-797.

Lynch MA (2004) Long-term potentiation and memory. Physiol Rev 84:87-136

Malenka R, Nicoll RA (1999) Long-term potentiation: a decade of progress? Science 285:1870-1874.

Maren S, Baudry M, Thompson RF (1992) Effects of the novel NMDA receptor antagonist, CGP 39551, on field potentials and the induction and expression of LTP in the dentate gyrus in vivo. Synapse 11:221-228.

McEchron MD, Disterhoft JF (1997) Sequence of single neuron changes in CA1 hippocampus of rabbits during acquisition of trace eyeblink conditioned responses. J Neurophysiol 78:1030-1044.

McEchron MD, Tseng W, Disterhoft JF (2003) Single neurons in CAl hippocampus encode trace interval duration during trace heart rate (fear) conditioning in rabbit. J Neurosci 23:1535-1547.

McNaughton BL, Douglas RM, Goddard GV (1978) Synaptic enhancement in fascia dentata: cooperativity among coactive afferents. Brain Res 157:277-293.

McNaughton BL, Barnes CA, Rao G, Baldwin J, Rasmussen M (1986) Longterm enhancement of hippocampal synaptic transmission and the acquisition of spatial information. J Neurosci 6:563-571.

Mokin M, Keifer J (2005) Expression of the immediate-early gene-encoded protein Egr-1 (zif268) during in vitro classical conditioning. Learn Mem 12:144-149.

Morris RGM, Moser EI, Riedel G, Martin SJ, Sandin J, Day M, O'Carroll CO (2003) Elements of a neurobiological theory of the hippocampus: the role of activity-dependent synaptic plasticity in memory. Phil Trans R Soc Lond B 358:773-786.

Moser EI, Krobert KA, Moser MB, Morris RGM (1998) Impaired spatial learning after saturation of long-term potentiation. Science 281:2038-2042.

Moyer Jr JR, Deyo RA, Disterhoft JF (1990) Hippocampectomy disrupts trace eye-blink conditioning in rabbits. Behav Neurosci 104:243-252. 
Múnera A, Gruart A, Muñoz MD, Fernández-Más R, Delgado-García JM (2001) Discharge properties of identified CA1 and CA3 hippocampus neurons during unconditioned and conditioned eyelid responses in cats. J Neurophysiol 86:2571-2582.

Nader K (2003) Memory traces unbound. Trends Neurosci 26:65-72.

Nader K, Schafe GE, LeDoux JE (2000) The labile nature of consolidation theory. Nat Rev Neurosci 1:216-219.

Namba T, Morimoto K, Sato K, Yamada N, Kuroda S (1994) Antiepileptogenic and anticonvulsant effects of NBQX, a selective AMPA receptor antagonist, in the rat kindling model of epilepsy. Brain Res 638:36-44.

Nicoll RA (2003) Expression mechanisms underlying long-term potentiation: a postsynaptic view. Philos Trans R Soc Lond Biol Sci 358:721-726.

Otnæss MK, Brun VH, Moser MB, Moser EI (1999) Pretraining prevents spatial learning impairment after saturation of hippocampal long-term potentiation. J Neurosci 19:1-5.

Parada J, Czuczwar SJ, Turski WA (1992) NBQX does not affect learning and memory tasks in mice: a comparison with D-CPPene and ifenprodil. Brain Res Cogn Brain Res 1:67-71.

Paxinos G, Franklin KBJ (2001) The mouse brain in stereotaxic coordinates. London: Academic.

Porras-García E, Cendelin J, Domínguez-del-Toro E, Vožeh F, DelgadoGarcía JM (2005) Purkinje cell loss affects differentially the execution, acquisition and prepulse inhibition of skeletal and facial motor responses in Lurcher mice. Eur J Neurosci 21:979-988.

Sanchez-Andres JV, Alkon DL (1991) Voltage-clamp analysis of the effects of classical conditioning on the hippocampus. J Neurophysiol 65:796-807.

Sanders MJ, Fanselow MS (2003) Pre-training prevents context fear conditioning deficits produced by hippocampal NMDA receptor blockade. Neurobiol Learn Mem 80:123-129.

Sara SJ (2000) Retrieval and reconsolidation: toward a neurobiology of remembering. Learn Mem 7:73-84.

Schwartzkroin PA (1986) Regulation of excitability in hippocampal neurons. In: The hippocampus (Isacson RL, Pribram KH, eds), pp 113-136. New York: Plenum.

Servatius RJ, Shors TJ (1996) Early acquisition, but not retention, of classically conditioned eyeblink responses is $N$-methyl-D-aspartate (NMDA) receptor dependent. Behav Neurosci 110:1040-1048.

Squire LR, Alvarez P (1995) Retrograde amnesia and memory consolidation: a neurobiological perspective. Curr Opin Neurobiol 5:169-177.

Takatsuki K, Kawahara S, Kotani S, Fukunaga S, Mori H, Mishina M, Kirino Y (2003) The hippocampus plays an important role in eyeblink conditioning with a short trace interval in glutamate receptor subunit $\delta 2 \mathrm{mu}$ tant mice. J Neurosci 23:17-22.

Thompson RF (1988) The neural basis of basic associative learning of discrete behavioral responses. Trends Neurosci 11:152-155.

Weisz DJ, Clark GA, Thompson RF (1984) Increased responsivity of dentate granule cells during nictitating membrane response conditioning in rabbit. Behav Brain Res 12:145-154.

Woody CD (1986) Understanding the cellular basis of memory and learning. Annu Rev Psychol 37:433-493. 